\title{
Complex video-assisted thoracoscopic surgery (VATS) sub-segmentectomy of S3b: case report and analysis of a single-center S3 segmentectomy series
}

\author{
Filipe Azenha^, Gregor J. Kocher \\ Division of General Thoracic Surgery, Bern University Hospital, University of Bern, Bern, Switzerland \\ Correspondence to: Gregor J. Kocher, MD, MBA. Division of General Thoracic Surgery, Bern University Hospital, CH-3010 Bern, Switzerland. \\ Email: gregor.kocher@insel.ch.
}

\begin{abstract}
A 58-year-old female patient was referred to our department with a history of heavy smoking and a newly diagnosed nodule in the right upper lobe. In 2018 the patient had been surgically treated for rectal carcinoma followed by adjuvant chemotherapy. Since, due to the location of the nodule, a transbronchial or transthoracic biopsy was not feasible, we were consulted for a surgical approach. The central location of the lesion did not allow for a wedge resection. In order to spare as much healthy lung parenchyma as possible and assure a sufficient safety margin we planned and performed a uniportal video-assisted thoracoscopic surgery (VATS) S3b sub-segmentectomy of the right upper lobe. To highlight the segmental margins, we used indocyanine green after division of the segmental vascular and bronchial structures. In our experience, segmentectomy is a good surgical approach for primary lung tumors smaller than $2 \mathrm{~cm}$ in size and in patients with restricted lung function as well as for the resection of centrally located metastasis. In the case of metastasectomy, subsegmentectomy can be of value in order to spare as much healthy lung parenchyma as possible. We present our preferred surgical technique including a video of such a surgical procedure and in addition we present an analysis of 36 patients who have undergone uniportal S3 segmentectomy at our institution.
\end{abstract}

Keywords: Uniportal video-assisted thoracoscopic surgery (uniportal VATS); segmentectomy; sublobar anatomical resection; segment III resection; case report

Received: 07 June 2021; Accepted: 26 September 2021; Published online: 13 October 2021.

doi: 10.21037 /jovs-21-35

View this article at: https://dx.doi.org/10.21037/jovs-21-35

\section{Introduction}

Recent studies have shown that cancer-specific survival of patients undergoing segmentectomy for stage I lung cancer does not significantly differ from patients undergoing lobectomy $(1,2)$. Its superiority when compared to subanatomical resection has already well been documented (3). Additionally, segmentectomy allows to preserve valuable lung parenchyma in patients with restricted lung function or who may need multiple lung resections as it can be the case when dealing with lung metastases $(4,5)$. In order to perform anatomical segmentectomy it is fundamental to be aware of the patient specific anatomy and to use landmarkers for orientation. This can be achieved by thorough study of the preoperative computed tomography (CT) scan and intraoperatively by the injection of indocyanine green (ICG) in order to expose the segmental margins. We present the following case report in accordance with the CARE reporting checklist (available at https://jovs.amegroups. com/article/view/10.21037/jovs-21-35/rc) followed by an analysis of a series of 36 patients who have undergone

^ ORCID: 0000-0003-2883-5205. 


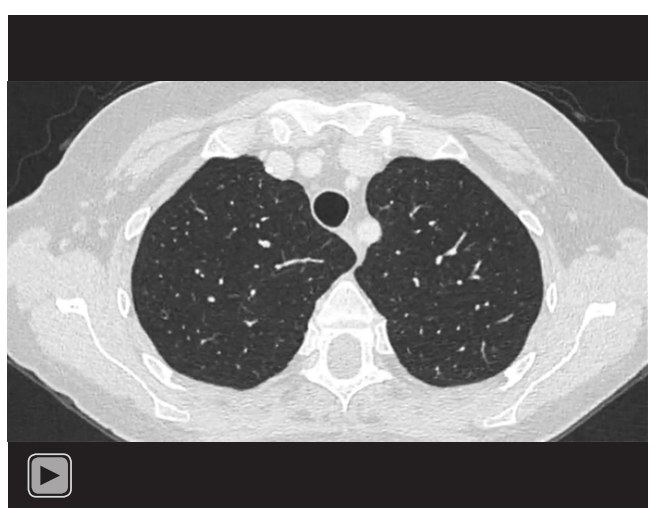

Video 1 Uniportal video-assisted thoracoscopic surgery right S3b subsegmentectomy.

uniportal S3 segmentectomy at our institution.

\section{Case presentation}

In December 2020, a 58-year-old female patient was referred to our department to discuss surgical resection of a suspect nodule in the right upper lobe. The patient had a smoking history of 30 pack-years (PY) and had been surgically treated for rectal carcinoma in 2018 followed by adjuvant chemotherapy. CT showed a nodule in segment 3 of the right upper lobe. At our institution we use multiplanar CT reconstruction images in order to identify anatomical landmarks such as veins, arteries, bronchus to navigate through the operation (Video 1 timestamp: 00:29-00:45). 3D reconstruction can be an important tool for surgical planning but is not essential to perform minimally invasive segmentectomies. The patient signed an informed consent form and uniportal VATS S3b subsegmentectomy was planned.

All procedures performed in this study were in accordance with the ethical standards of the institutional and/or national research committee(s) and with the Helsinki Declaration (as revised in 2013). Written informed consent was obtained from the patient for publication of this case report and the accompany video. A copy of the written consent is available for review by the editorial office of this journal.

\section{Surgical technique}

An incision of $3 \mathrm{~cm}$ was performed in the $4^{\text {th }}$ intercostal space centered on the anterior axillary line. After radical mediastinal lymphadenectomy of stations $2 \mathrm{R}, 4 \mathrm{R}, 9 \mathrm{R}$, $8 \mathrm{R}$ and 7 the pleura was opened at the hilum in order to free up the upper pulmonary vein. We then continued along the parenchymal line in order to expose the right pulmonary artery as well as the right main bronchus. After identifying the truncus anterior we continued the dissection in order to expose the artery corresponding to the S3b segment and divided A3b after its take-off using a powered vascular stapler. Since the horizontal fissure was incomplete, we opened it using a powered stapler in tunnel technique following the S2 vein into the oblique fissure. After opening the fissure, the vein draining segment 3 was identified and divided using a powered vascular stapler. To safely identify the bronchus, we followed the S2 vein, which crosses the $\mathrm{S} 3$ bronchus caudally. After dissection of the $\mathrm{S} 3 \mathrm{~b}$ subsegmental bronchus we were able to divide it using a powered vascular stapler as well. We usually double-check the segmental margins and the correct extent of resection as well as the sufficient ventilation and perfusion of the remaining lung using both, the ventilation method as well as ICG in combination with near infrared thoracoscopy. First, the lung was slowly re-ventilated to identify the segmental margins; second, $6 \mathrm{mg}$ of ICG were injected and the segmental margins were again checked. Especially in patients undergoing subsegmental resections, due to a higher incidence of anatomical variations on the segmental and subsegmental level, this double-checking method is often worthwhile. Also, in patients with lung emphysema, segmental margins can be overestimated using the ventilation technique alone. The specimen was then retrieved in a sterile glove and the nodule was clearly identified by touch in the center of the specimen. After checking for air leaks and hemostasis, a 20-French chest tube was inserted, and the surgical access was closed using absorbable sutures.

\section{Results}

Histological analysis revealed a single metastasis of the previously diagnosed rectal carcinoma. The chest tube was removed on postoperative day 1 and the patient was discharged the day after. Follow-up CT at 3 months showed no signs of local recurrence. After interdisciplinary discussion follow-up CT at 6 months was recommended. The patient has no respiratory complaints and wound healing was unremarkable.

Between May 2016 and December 2020, we have performed a total of 36 uniportal VATS S3 resections. Ten 
on the left and 26 right S3 resections. Mean patient age was 66 years (range, 42-80 years). Histological analysis revealed 11 non-small cell lung cancers (NSCLCs), 4 hamartomas, 2 typical carcinoid tumors and 14 metastasis of a primary non-lung related tumors. Median tumor size for primary NSCLC was $1.7 \mathrm{~cm}$ (range, 0.4-4 cm). Median length of stay was 3 days (range, 1-10 days). Thirty-day mortality rate was $0 \%$.

\section{Conclusions}

In our experience, S3 segmentectomy is a good surgical approach for primary lung tumors smaller than $2 \mathrm{~cm}$ in size as well as for the resection of centrally located metastasis. In the latter case subsegmentectomy can even be the preferred option in selected cases. Both approaches are associated with very low morbidity and mortality rates. Additionally, in patients with larger primary lung tumors and restricted lung function this lung-sparing surgical approach is a good treatment option and has the advantage of providing a histopathological diagnosis together with lymph node clearance as opposed to stereotactic body radiotherapy (SBRT).

\section{Acknowledgments}

Funding: None.

\section{Footnote}

Provenance and Peer Review: This article was commissioned by the Guest Editor (Michel Gonzalez) for the series "VATS Segmentectomy" published in Fournal of Visualized Surgery. The article has undergone external peer review.

Reporting Checklist: The authors have completed the CARE reporting checklist. Available at https://jovs.amegroups. com/article/view/10.21037/jovs-21-35/rc

Peer Review File: Available at https://jovs.amegroups.com/ article/view/10.21037/jovs-21-35/prf

Conflicts of Interest: Both authors have completed the ICMJE uniform disclosure form (available at https://jovs. amegroups.com/article/view/10.21037/jovs-21-35/coif). The series "VATS Segmentectomy" was commissioned by the editorial office without any funding or sponsorship. The authors have no other conflicts of interest to declare.
Ethical Statement: The authors are accountable for all aspects of the work in ensuring that questions related to the accuracy or integrity of any part of the work are appropriately investigated and resolved. All procedures performed in this study were in accordance with the ethical standards of the institutional and/or national research committee(s) and with the Helsinki Declaration (as revised in 2013). Written informed consent was obtained from the patient for publication of this case report and accompanying video. A copy of the written consent is available for review by the editorial office of this journal.

Open Access Statement: This is an Open Access article distributed in accordance with the Creative Commons Attribution-NonCommercial-NoDerivs 4.0 International License (CC BY-NC-ND 4.0), which permits the noncommercial replication and distribution of the article with the strict proviso that no changes or edits are made and the original work is properly cited (including links to both the formal publication through the relevant DOI and the license). See: https://creativecommons.org/licenses/by-nc-nd/4.0/.

\section{References}

1. Handa Y, Tsutani Y, Mimae T, et al. Oncologic Outcomes of Complex Segmentectomy: A Multicenter Propensity ScoreMatched Analysis. Ann Thorac Surg 2021;111:1044-51.

2. Zeng $W$, Zhang $W$, Zhang J, et al. Systematic review and meta-analysis of video-assisted thoracoscopic surgery segmentectomy versus lobectomy for stage I non-small cell lung cancer. World J Surg Oncol 2020;18:44.

3. Zhang H, Liu C, Tan Z, et al. Segmentectomy Versus Wedge Resection for Stage I Non-Small Cell Lung Cancer: A Meta-analysis. J Surg Res 2019;243:371-9.

4. Tane S, Nishio W, Nishioka Y, et al. Evaluation of the Residual Lung Function After Thoracoscopic Segmentectomy Compared With Lobectomy. Ann Thorac Surg 2019;108:1543-50.

5. Charloux A, Quoix E. Lung segmentectomy: does it offer a real functional benefit over lobectomy? Eur Respir Rev 2017;26:170079.

doi: $10.21037 /$ jovs-21-35

Cite this article as: Azenha F, Kocher GJ. Complex videoassisted thoracoscopic surgery (VATS) sub-segmentectomy of $\mathrm{S} 3 \mathrm{~b}$ : case report and analysis of a single-center S3 segmentectomy series. J Vis Surg 2023;9:17. 